\title{
VOLUNTARIOS CONTRA LA REPÚBLICA: EL REQUETÉ ALAVÉS
}

\author{
GERMÁN RUIZ LLANO
}

berdiales42@hotmail.com

\section{Resumen:}

En la década de los años 30 del siglo XX, Álava era una provincia española mayoritariamente agrícola y con una población profundamente católica, con una escasa violencia sociopolítica y altos niveles de distribución de la propiedad. Sin embargo, en julio de 1936, se convirtió en una de las provincias con un mayor porcentaje de población masculina alistada voluntariamente para combatir contra la II República. El porqué y el cómo de aquella parte de la movilización antirrepublicana, proveniente sobre todo del mundo rural tradicional, centran el presente artículo.

\section{Palabras clave:}

Álava- Requeté - Movilización - II República - Guerra Civil

\begin{abstract}
:
In the decade of the 30's of the 20th century, Álava was a predominantly agricultural Spanish province. It had a deeply Catholic population, with little socio-political violence and high levels of property distribution. However, in July 1936, it became one of the provinces with a higher percentage of male population voluntarily enlisted to fight against the Second Republic. In this article we study the reasons of the anti-republican mobilization from the traditional rural world.
\end{abstract}

\section{Keywords:}

Álava - Requeté - Movilization - Second Republic - Civil War 


\title{
VOLUNTARIOS CONTRA LA REPÚBLICA: EL REQUETÉ ALAVÉS
}

\author{
GERMÁN RUIZ LLANO \\ berdiales42@hotmail.com
}

\section{Introducción}

El voluntariado y la movilización a favor de la sublevación militar de julio de 1936 ha sido un tema escasamente tratado por la historiografía de la Guerra Civil española, a pesar de ser un aspecto importantísimo en el devenir del conflicto y que, como comentó en su momento Julio Aróstegui, fue una de las causas principales para convertir una sublevación militar semifracasada en una contienda en toda regla ${ }^{1}$.

En este sentido, han sido escasos los autores que se han acercado al fenómeno de las milicias derechistas antes y durante la contienda. Serían de destacar autores como Casas de la Vega, cuya obra Las Milicias Nacionales, aunque desde una óptica profranquista y un tanto confusa en su exposición, fue el primer acercamiento global al tema ${ }^{2}$; Eduardo González Calleja, que ha analizado los años republicanos ${ }^{3}$; el citado Aróstegui, que teorizó sobre el fenómeno miliciano y escribió una historia militar del Requeté carlista ${ }^{4}$; Javier Ugarte Tellería, que ahondó en las raíces socio-culturales de la movilización antirrepublicana en el País Vasco y Navarra y los estudios sobre Galicia de Julio $\operatorname{Prada}^{6}$, así como alguna que otra aportación de índole memorialista ${ }^{7}$.

En el presente artículo se va a analizar la movilización antirrepublicana que se dio en la provincia de Álava ${ }^{8}$, situada en el País Vasco, a través de su milicia derechista más numerosa y poderosa': el

\footnotetext{
1 Aróstegui, Julio, Porqué el 18 de julio y después, Madrid, Flor del Viento, 2006, págs. 199-204.

2 Casas de la Vega, Rafael, Las Milicias Nacionales. Madrid, Editora Nacional, 1977.

${ }^{3}$ González Calleja, Eduardo, Contrarrevolucionarios. Radicalización violenta de las derechas durante la Segunda República, 1931 1936, Madrid, Alianza, 2011.
}

4 Aróstegui, Julio, Combatientes requetés en la guerra civil española (1936-1939), Madrid, La Esfera de los Libros, 2013; Aróstegui, Julio, "Sociedad y milicias en la guerra civil española, 1936-1939, una reflexión metodológica", en Castillo, Santiago (coordinador). Estudios de Historia de España: homenaje a Manuel Tuñón de Lara. Volumen 2, Santander, Universidad Menéndez Pelayo, 1981, págs. 307-326; Aróstegui, Julio, “Conflicto social e ideología de la violencia”, en García Delgado, José Luis (editor), España, 1898-1936: Estructuras y cambio. Coloquio de la Universidad Complutense sobre la España contemporánea, Madrid, Universidad Complutense, 1984, pp. 309-344; Aróstegui, Julio, "La incorporación del voluntariado de Navarra al ejército de Franco. Fundamentos sociohistóricos de una opción ideológica", Sistema, 47, 1982, págs. $77-110$.

${ }^{5}$ Ugarte Tellería, Javier, La nueva Covadonga insurgente. Orígenes sociales y culturales de la sublevación de 1936 en Navarra y el País Vasco, Madrid, Biblioteca Nueva, 1998; Ugarte Tellería, Javier, "Aproximación a una sociografía de los milicianos alaveses en el ejército de Franco", Perspectiva Contemporánea, 1, 1988, págs. 51-78.

${ }^{6}$ Prada, Xulio, A dereita política ourensá: monárquicos, católicos e fascistas, Vigo, Universidad de Vigo, 2005; Prada, Julio, "Las milicias de segunda línea en la retaguardia franquista: el caso de Galicia”, Cuadernos de Historia Contemporánea, 33, 2011, págs. 255-273.

${ }^{7}$ Larraz Andía, Pablo y Sierra-Sesúmaga, Víctor, Requetés, de las trincheras al olvido, Madrid, La Esfera de los Libros, 2011.

8 Para una visión general de la movilización de los combatientes en la provincia, tanto de los forzosos como los provenientes de otras milicias ver Ruiz Llano, Germán, Alava una provincia en pie de guerra. Voluntariado y movilización durante la Guerra Civil, Bilbao, Ediciones Beta, 2016.

9 Para definir milicia política me remito a González Calleja: "formación de corte paramilitar (es decir, con organización, disciplina, jerarquía, instrucción y parafernalia castrenses sin pertenecer a una institución armada oficial) compuesta de forma voluntaria por ciudadanos civiles, e inspirada por doctrinas político-ideológicas específicas, bajo el control más 
Requeté, brazo armado de la Comunión Tradicionalista (CT), siglas bajo las que se articuló el carlismo durante los años republicanos ${ }^{10}$.

El carlismo era un movimiento político de carácter contrarrevolucionario, tradicionalista, católico, monárquico, antiliberal y ultraconservador que se remontaba a las luchas entre liberales y absolutistas del siglo XIX, protagonizando tres guerras civiles en aquel siglo ${ }^{11}$. Durante toda su existencia como movimiento organizado y de masas, hasta su virtual extinción durante los años 70 del siglo pasado, dio muestras de un gran dinamismo y flexibilidad organizativa e ideológica, aunque dentro de la ortodoxia antes marcada, que le permitieron sobrevivir durante más de un siglo.

Paradójicamente, la llegada de la II República revivió a un carlismo que comenzaba a dar muestras de decadencia, y que defendía la instauración de un sistema antiliberal y antidemocrático a través de una Monarquía tradicional y corporativa, bajo el lema "Dios-Patria-Rey", justificando el uso de la violencia desde el derecho público cristiano como resistencia frente a una República laica, vista como una tiranía ilegítima ${ }^{12}$. Consiguió amalgamar el sentir contrarrevolucionario de una parte de la sociedad española de ideas conservadoras y católicas que, tras el derrocamiento de la monarquía de Alfonso XIII, veía con temor al régimen republicano y su ideario reformista, considerándolos la antesala de una revolución social que destruiría a la religión católica y el orden social y económico establecido $^{13}$.

o menos estricto de un partido u organización similar (movimiento, coalición, federación de partidos, etcétera), cuya misión era el combate físico con el rival ideológico en todos los frentes, incluido el callejero". González Calleja, Eduardo, "El simbolismo de la violencia durante la Segunda República española, 1931-1936", en Ealham, Chris y Richards, Michael (editores), España fragmentada. Historia cultural y Guerra Civil española, Granada, Comares, 2010, pág. 50.

${ }^{10} \mathrm{El}$ carlismo era la fuerza política más antigua que pervivía en el siglo XX y, sin embargo, fue la primera y más eficiente a la hora de dotarse de una organización paramilitar. Desde la llegada a la jefatura carlista de Manuel Fal Conde, en mayo de 1934, éste defendió la vía insurreccional y se elaboraron planes claramente insurreccionales a partir de 1935. Aunque no se puede sobreestimar su importancia en la primavera de 1936 y la conspiración que llevaría al golpe de Estado, tampoco se puede minimizarla ya que, por ejemplo, el mismo fascismo español representado por Falange Española contaba con unas milicias menos organizadas y tenía una menor implantación. Otra cosa es su papel en la configuración política de la dictadura franquista. Como dijo Julio Aróstegui: "el legitimismo y el fascismo españoles de los años treinta resultaron sacrificados en el holocausto hecho a la restauración de los privilegios del mismo bloque oligárquico a quien amenazó la república reformista" (Aróstegui, Julio, Combatientes requetés..., op. cit., pág. 128). Sobre la configuración cultural e ideológica del nuevo régimen véase Gallego, Ferrán, El evangelio fascista. La formación de la cultura política del franquismo (1930-1950), Barcelona, Crítica, 2014.

${ }^{11}$ Para una visión del carlismo, tanto a nivel general como al específicamente alavés. Canal, Jordi, Banderas blancas, boinas rojas. Una historia política del carlismo, 1876-1939, Madrid, Marcial Pons, 2006; Canal, Jordi El carlismo. Dos siglos de contrarrevolución en España, Barcelona, RBA, 2006; Blinkhorn, Martin, Carlismo y contrarrevolución en España 1931-1939, Barcelona, Crítica, 1979; Pablo, Santiago de, La Segunda República en Álava. Elecciones, partidos y vida política, Bilbao, UPV, 1989; Rivera, Antonio y Pablo, Santiago de, Profetas del pasado. La conformación de una cultura política. III. Las derechas en Alava, Vitoria, Ikusager, 2014; Aróstegui, Julio, El carlismo alavés y la guerra civil de 1870-1876, Vitoria, Diputación Foral de Álava, 1970.

12 Canal, Jordi, El carlismo, op. cit., págs. 334-335; González Calleja, Eduardo, Contrarrevolucionarios, op. cit., págs. 57-66 y 195-196.

${ }^{13}$ Entendido como: "algo natural, inmutable e indiscutible, cuyo mantenimiento debe ser garantizado a toda costa y por todos los medios posibles, incluidos los violentos. Es, por tanto, una actitud más inmovilista que regresiva, que no admite variaciones sustanciales en la hegemonía social (con la primacía de los sectores de la gran burguesía y de la nobleza que acepta las consecuencias de los cambios en sentido capitalista), el sistema político (con el establecimiento y consolidación, (...) de un régimen liberal-parlamentario de sufragio restringido y con la potenciación de la Corona, de la Cámara Alta y de la Administración civil o militar), y la estructura económica, con la acrítica asunción del sistema capitalista basado en la propiedad personal, libre y plena de las desiguales relaciones de producción que lleva anejas, cuyo mantenimiento era básico para el desarrollo material y la prosperidad de los grupos dominantes (...) y que quedará progresiva e indisolublemente vinculada a otra de sus grandes obsesiones: el 'orden público' como manifestación violenta de su dominio directo en la sociedad política". González Calleja, Eduardo, "La defensa armada del 'orden social' durante la Dictadura de Primo de Rivera (1923-1930)", en VVAA, España entre dos siglos (1875-1931). Continuidad y cambio, Madrid, Siglo XXI, 1991, págs. 61-62. 
El Requeté fue la milicia política más poderosa de España durante la II República. Se había constituido en 1907 como un novedoso elemento movilizador de la juventud carlista, adaptado a la lucha urbana y más acorde con los nuevos tiempos que el insurreccionalismo rural del siglo anterior. Esta nueva milicia mantuvo diversos enfrentamientos contra republicanos y grupos anticlericales durante los últimos años de la Restauración (1876-1923), permaneciendo latente y con escasa relevancia hasta $1931^{14}$.

\section{E1 Requeté alavés: de la República al 18 de julio.}

Son pocas las noticias anteriores a la Guerra Civil disponibles sobre el Requeté alavés. Durante la Restauración se organizó en diversas localidades de la provincia, participando en las actividades públicas del carlismo: misas, desfiles, mítines, etcétera. ${ }^{15}$ También mantuvo algún incidente con los republicanos locales, como el acaecido en las elecciones municipales de noviembre de 1913, en el que grupos de ambas tendencias se enfrentaron a vergajazos en Vitoria, capital de la provincia, con el saldo de varios heridos ${ }^{16}$. A partir de aquel momento existe un silencio en las fuentes que se prolonga hasta 1931. Momento en que, con la fundación de Hermandad Alavesa (HA), marca electoral local de la CT en la provincia durante los años republicanos, se reconstituyó el Requeté, lo que trajo problemas con las nuevas autoridades, ya que en el artículo $\mathrm{n}^{\circ} 2$ de su reglamento se hablaba de ${ }^{17}$ :

“...constituir algo parecido a un «fascio» de Italia. Hubo entonces que decir al señor que lo presentó que en el artículo (...) por su especial redacción y vocabulario aparece como una entidad agresiva, suplantando a los Poderes públicos, que son los únicos encargados de mantener el orden."

HA consiguió amalgamar, bajo el liderazgo de José Luis Oriol y la preeminencia del carlismo ${ }^{18}$, a la mayoría de sensibilidades conservadoras de la provincia: monárquicos alfonsinos, católicos independientes, antiguos partidarios de la dictadura de Primo de Rivera (1923-1930), etcétera, convirtiéndose en la fuerza política más poderosa de la provincia, y haciendo patente su negativa a reconocer a la República más que como el "régimen político establecido de hecho en España", con el clarificador lema "Religión-Fueros-Familia-Orden-Trabajo-Propiedad"19.

Si bien la proclamación de la II República en Álava, al igual que en el resto de España, se vivió con general entusiasmo, las enormes expectativas y resistencias que acarreó el programa reformista de sus primeros gobiernos sobre las cuestiones agraria, militar, educativa, religiosa, territorial, etcétera, hicieron que los problemas y conflictos comenzaran a plantearse casi de inmediato. Aunque en Álava cuestiones como la reforma agraria no tuvieron importancia al ser una provincia donde la propiedad agrícola estaba repartida de manera más o menos equitativa, las cuestiones religiosa y social saltaron a la palestra de inmediato ${ }^{20}$.

\footnotetext{
14 González Calleja, Eduardo, La razón de la fuerza: orden público, subversión y violencia politica en la crisis de la Restauración (1875-1917), Madrid, CSIC, 1998, págs. 165-167, 207-218 y 477-508; Canal, Jordi. Banderas, op. cit., págs. $29-34$.

${ }^{15}$ Heraldo Alavés. (HA). Vitoria. 29-I-1912; 1-VII-1912; 7 y 14-VII-1913; 22-IX-1913; 9-XII-1913.

${ }^{16} \mathrm{H}$ A. Vitoria. 10-XI-1913.

${ }^{17}$ La Libertad (LL) y HA. Vitoria. 15-X-1931.

18 Se trataba de un acaudalado arquitecto y financiero que, tras una breve carrera política durante los años de la Restauración, decidió retomarla tras la proclamación de la República. Fue candidato a Cortes por la provincia durante todo el período republicano, resultando elegido como segundo candidato más votado en 1931 y el primero en 1933 y 1936. Además, se convirtió en uno de los miembros más importantes e influyentes de la CT a nivel nacional durante aquellos años. Blinkhorn, Martin, Carlismo, op. cit., págs. 113, 195 y 200-201; de Pablo, Santiago, La Segunda, op. cit., págs. 60-61.

19 Archivo Histórico Provincial de Álava. 27466-A; HA. Vitoria. 6 y 13-VI-1931.

20 También tuvo importancia la cuestión del estatuto de autonomía vasco, pero fue menor, sobre todo si se compara con las provincias de Vizcaya y Guipúzcoa, donde hubo enfrentamientos entre republicanos y nacionalistas vascos que
} 
El primer problema al que tuvo que enfrentarse el nuevo régimen fue la expulsión del obispo de Vitoria, Mateo Múgica, que se había ganado la animadversión de los republicanos locales por sus intromisiones electorales y que fue expulsado de España en mayo de 1931 en medio de las protestas de la opinión pública católica. También causaron gran alarma la llegada de noticias sobre la quema de conventos y edificios religiosos ocurridos en diversas ciudades españolas durante aquel mes. Paralelamente, las mociones demagógicas de los concejales de ideas más anticlericales del Ayuntamiento de Vitoria dividieron al republicanismo local y dañaron su imagen ${ }^{21}$.

A su vez, las sucesivas normas y leyes laicistas del Gobierno republicano hicieron que desde los ámbitos católicos, especialmente en el mundo rural, creciera una resistencia y oposición, tanto a nivel popular como desde los ayuntamientos. Interpretándolas como una persecución, fruto del sectarismo de los gobernantes republicanos, y el comienzo de los agravios para con los católicos. Por ejemplo, en febrero-marzo de 1932, el gobernador civil de la provincia amonestó y multó al alcalde y varios vecinos de la localidad de Yécora cuando repusieron el crucifijo en la escuela local tras ser retirado en virtud de las nuevas leyes, que prohibían la exhibición de símbolos religiosos en los centros educativos. Incidentes como este, que se repitieron en varias localidades, crearon un progresivo malestar en el mundo rural al sentirse su población atacada en sus más íntimas creencias $^{22}$.

Sin embargo, la cuestión social fue el principal foco de conflicto durante aquellos años debido al crack del 29 y su secuela más visible, el aumento del paro obrero. El sindicato anarquista Confederación Nacional del Trabajo (CNT), viéndose a sí mismo como el único representante legítimo del proletariado al no estar mediatizado por la política, frente a otros como la socialista Unión General de Trabajadores, adoptó una estrategia de intensa movilización de su militancia con la intención de acelerar la llegada de una revolución social que pondría fin al capitalismo y las desigualdades. Para conseguirlo, realizó todo tipo de actividades violentas: sabotajes, boicots, insurrecciones, huelgas, etcétera, que en el caso alavés se saldaron con los asesinatos en Vitoria de un policía municipal y un sereno y con un alzamiento revolucionario que proclamó el comunismo libertario en la localidad de Labastida en diciembre de $1933^{23}$.

Aunque la estrategia de la CNT fue fácilmente desbaratada por las autoridades, la percepción en los ámbitos más conservadores de que la Revolución había llegado y que quizá la próxima vez no fuera derrotada, lo que supondría el fin de sus modos de vida, propiedades y creencias, supuso una radicalización de sus posturas ${ }^{24}$.

Estos temores volverían a repetirse y acrecentarse en octubre del año siguiente, cuando, tras el triunfo del centro-derecha en las elecciones de diciembre de 1933 y la entrada en el Gobierno de la contrarrevolucionaria, conservadora y católica Confederación Española de Derechas Autónomas (CEDA), los socialistas desencadenaron una huelga general revolucionaria al temer que, una vez en el poder, la CEDA pusiera fin a la República como un régimen democrático y reformista. Este intento se saldó con intensos enfrentamientos y una brutal represión y, si bien en Álava apenas

\footnotetext{
se saldaron con varias víctimas mortales. Para los datos generales del período me remito a González Calleja, Eduardo, Cobo Romero, Francisco, Martínez Rus, Ana y Sánchez Pérez, Francisco, La Segunda República Española, Barcelona, Pasado \& Presente, 2015.

${ }^{21}$ Pablo, Santiago de, La Segunda, op. cit. págs.35-36, 131-133 y 138-141; Rivera, Antonio, La utopía futura. La conformación de una cultura politica. I. Las izquierdas en Alava, Vitoria, Ikusager, 2014, págs. 198 y 205-209.

${ }^{22} \mathrm{H}$ A. Vitoria. 10 y 11-II-1932; 15 y 28-III-1932; más incidentes, protestas y multas en HA. Vitoria. 9,10 y 13-II-1932; 10, 18 y 29-III-1932; 1-V-1932; LL. Vitoria. 28-I-1932; 29-II-1932.

23 Pablo, Santiago de, "La CNT y los sucesos revolucionarios de Labastida en diciembre de 1933", Kultura, 8, 1985, págs. 105-116; Rivera, Antonio, La utopía futura, op. cit., págs. 252-256; una visión general en Casanova, Julián, De la calle al frente. El anarcosindicalismo en España, Barcelona, Crítica, 1997.

${ }^{24}$ Ugarte Tellería, Javier, La nueva, op. cit., págs. 25-26.
} 
tuvo repercusión, el conservadurismo local cerró filas y expresó su apoyo al Ejército y fuerzas de orden público, organizando colectas y homenajes en su favor ${ }^{25}$.

Las alarmas de estos sectores sociales volvieron a dispararse en febrero de 1936, cuando la coalición del Frente Popular (FP), formada por todo el arco político del centro-izquierda excepto la CNT ganó las elecciones a Cortes, formándose un nuevo Gobierno de republicanos moderados apoyado parlamentariamente por la izquierda obrera, con un programa que incluía la reanudación de las reformas interrumpidas en el bienio 1934-1935. En Álava, el triunfo del FP supuso una reanudación de las luchas sociales y la movilización sindical que inquietó a los sectores conservadores, temor atizado por la prensa derechista, en el caso concreto de Álava el diario carlista Pensamiento Alavés, propiedad de José Luis Oriol, llegando a identificar al Gobierno del FP y a la República con la revolución, llamando abiertamente al golpismo para acabar con ambos. El protagonismo de la violencia política en la provincia pasó ahora a los carlistas, que fueron los actores fundamentales en una serie de incidentes en varias localidades de la provincia, principalmente Labastida y Laguardia, donde la convivencia entre vecinos llegó a hacerse insostenible ${ }^{26}$.

Finalmente, en julio se produjo la sublevación militar contra la II República. El golpe fracasó en las grandes ciudades, pero triunfó fácilmente en Álava, donde recibió el apoyo de la mayoría de la población, convirtiéndose en la segunda provincia española en porcentaje de población que se alistó voluntariamente y la tercera en número total de voluntarios ${ }^{27}$.

Las referencias al Requeté durante los años republicanos son muy dispersas y sólo hablan de su presencia en actos públicos, como funerales, mítines, elecciones, etcétera. A la altura de 1935, según la propia prensa carlista, había repartidos por toda la provincia alrededor de 350 requetés y en la primavera de 1936, se calculaba su número en unos $1.000^{28}$.

De sus actividades contra la República, lógicamente, no existen casi datos. La primera información de este tipo nos la encontramos en agosto de 1935, cuando fue interceptado en Vitoria un envío de uniformes militares, lo que motivó un registro de la sede de HA. También, durante la primavera de 1936, sus entrenamientos paramilitares fueron denunciados al Gobierno Civil ${ }^{29}$.

Por su parte, José Luis Oriol, el 4 de junio de 1936 en una reunión con el general Mola, jefe de la conspiración militar, comprometió su fortuna personal y al Requeté alavés con la sublevación militar. Este compromiso quedó definitivamente sellado el 9 de julio en la reunión que mantuvo con el teniente coronel Camilo Alonso Vega, uno de los jefes de la guarnición vitoriana, en la que expuso sus aspiraciones una vez triunfara la sublevación: "Reorganización de todos los municipios y Diputación de Álava. Restablecimiento del Crucifijo en las escuelas y de la bandera bicolor" ${ }^{30}$. El 13 de julio Oriol, reunido con la Junta Carlista de Álava, ultimó los detalles de la movilización y el 18 se preparó, en coordinación con los militares, el reclutamiento y llegada a Vitoria de los requetés de los pueblos ${ }^{31}$.

Tras la proclamación del estado de guerra en Vitoria la mañana del 19 de julio afluyeron de inmediato hacia Vitoria contingentes de voluntarios para ser armados y encuadrados, en una

\footnotetext{
${ }^{25}$ Pensamieto Alavés. (PA). y LL. Vitoria. X y XI-1934.

${ }^{26}$ El llamamiento en PA. Vitoria. 3-III-1936; los incidentes en Álava Republicana. (AR). Vitoria. 4-IV-1936; 9-V-1936; $P A$ y LL. Vitoria. 30-III-1936; 2 y 5-IV-1936.

${ }^{27}$ En cuanto a porcentaje de población, Navarra sería la primera y, en cuanto a su número, las primeras serían Navarra y La Rioja. Las comparaciones entre diferentes provincias en Casas de la Vega, Rafael, Las Milicias Nacionales, op. cit. ${ }^{28}$ HA. Vitoria. 12-X-1931; PA. Vitoria. 24-I-1936; 30-VI-1936;Boletin de Orientación Tradicionalista. Madrid. 21-IV-1935; Archivo de la Universidad de Navarra. Fondo Fal Conde. C. 257-36.

${ }^{29}$ Los uniformes en AR. Vitoria. 17-VIII-1935; LL. Vitoria. 26 y 27-VIII-1935; PA. Vitoria. 22-X-1935; La guerra civil en Euzkadi. 136 testimonios inéditos recogidos por José Miguel de Barandiarán, Milafranga-Villefranque, Bidasoa, 2005, pág. 413; lasdenuncias en la misma obra, págs. 282, 302 y 413.

30 Arrarás, Joaquín, Historia de la Cruzada Española. Vol. 3, Madrid, Datafilms, 1984, págs. 404-406 y 499.

${ }^{31}$ Ugarte Tellería, Javier, La nueva, op. cit., pág. 109.
} 
movilización que en algunos lugares tuvo caracteres masivos y en los que las antiguas redes sociales, familiares, vecinales y clientelares jugaron un papel de primera importancia. Desde Vitoria se enviaron emisarios a todos los pueblos donde había personas comprometidas. Estos, a su vez, jugaron un importante papel en la movilización al ser hijos de familias de clase media y alta, bien conocidos en los pueblos a los que iban y donde sus familias tenían amistades y relaciones clientelares y de patronazgo ${ }^{32}$.

Las modalidades de movilización fueron variadas y heterogéneas según las circunstancias de cada localidad. Hubo lugares con auténticas levas masivas de voluntarios donde prevaleció el entusiasmo, como las realizadas en el municipio de Berantevilla, en el cual la labor de su alcalde, el carlista Esteban Sáenz de Ugarte, fue decisiva. Ugarte, persona de enorme prestigio e influencia, consiguió levantar entre julio y septiembre de 1936 al $16 \%$ de la población masculina local como voluntaria en el Requeté. De esta manera relataba un testigo la movilización de los días 18 y 19 de julio $^{33}$ :

“Tan pronto fueron cortadas las conferencias telefónicas el sábado día 18 de julio se dio la voz de alerta entre los nuestros (...). Con la intranquilidad propia de estos casos se esperaba con verdadero deseo la orden de movilización que por fin llegó por escrito y con las garantías necesarias a las nueve de la noche del citado sábado y como movidos por un resorte todos acudieron a recibir instrucciones y se prepararon para cualquier eventualidad. (...)

"Durante la noche recorrieron algunos de nuestros requetés los pueblos del Ayuntamiento para que los comprometidos acudieran al llamamiento y aunque debido a las inaplazables tareas de recolección no todos cumplieron es de notar que otros los sustituyeron con entusiasmo y casados y solteros para las ocho de la mañana en número de cuarenta estaban preparados para ser trasladados a donde fuera necesario, hasta que por fin a las seis de la tarde llegaron órdenes de traslado a Vitoria en un auto que llegó al efecto, lo que se hizo en medio de gran entusiasmo y quedando unos treinta requetés de reserva de alguna edad para la custodia y defensa del pueblo.

"Durante el día del domingo y para mejor atender el orden y al cargo de la Alcaldía el que pocos días antes había sido multado, nuestro po[p]ular alcalde don Esteban S. de Ugarte, siendo su primer acuerdo colocar el Santo Crucifijo en las escuelas de la villa, que se verificó inmediatamente de acuerdo con la autoridad eclesiástica en medio de gran entusiasmo y volteo de campanas en solemne procesión presidida por nuestras autoridades, terminando el acto con patrióticas arengas por parte de las citadas autoridades civil y eclesiástica."

En otros sitios, la movilización topó con alguna dificultad y se obligó a alistarse a algunos mozos mediante la coacción o la obligación moral, como ocurrió en ciertos casos en las localidades de Fresneda, Espejo y Osma. Allí donde la convivencia se había roto, la situación era enconada y los incidentes entre vecinos habían sido graves, como Labastida o Laguardia, la movilización fue rápida, masiva y sencilla. Hubo localidades donde el reclutamiento se hizo de manera espontánea e improvisada. En Espejo, un veraneante natural del pueblo pero residente en Bilbao, Manuel Ramírez Escudero, con influencia, prestigio y relaciones de patronazgo en la localidad, organizó una milicia con el rimbombante nombre de Milicias Armadas de Valdegovía al Servicio de España, reclutando a los jóvenes del pueblo. El 19 de julio marchó a Vitoria, volviendo con un camión lleno de armas que repartió entre los voluntarios, participando en varios combates contra las milicias

32 Ugarte Tellería, Javier. La nueva, op. cit., págs. 109-116; García de Albéniz, Felipe, Álava por Dios y por España, Vitoria, Editorial Social Católica, 1936, págs. 36-38.

${ }^{3} \mathrm{P} A$. Vitoria. 22-VIII-1936. 
republicanas hasta su disolución en septiembre, pasando a integrarse la mayoría de sus miembros en las filas del Requeté ${ }^{34}$.

En otros lugares, la recluta se realizó de manera comunitaria. En el municipio de ArrazuaUbarrundia, colindante con la provincia de Guipúzcoa, en la que no triunfó la sublevación, durante los primeros días de la contienda se sufrieron varias incursiones por parte de milicianos republicanos. Sin embargo, la vida continuó sin grandes alteraciones hasta que aquellas se hicieron insoportables. Para pedir protección, se envió una comisión de vecinos a Vitoria para entrevistarse con el coronel Cándido Fernández Ichaso, gobernador civil de la provincia tras el triunfo de la sublevación. Este exigió a cambio que salieran del municipio voluntarios para el Requeté. Al volver y dar noticia de las exigencias de Ichaso comenzó la recluta, realizándose a través de la reunión de los concejos de los pueblos, en los cuales se decidió cuántos y quiénes iban a ser los alistados según las disponibilidades de cada familia. Por ejemplo, en la localidad de Ullívarri-Gamboa, iban a ser "cinco individuos de las casas en que mayor número de personal existe". De esta manera, sin que hubiera ideas políticas de por medio, varios jóvenes del municipio se vieron involucrados en un conflicto en el que no tenían nada que ver. En este caso, era la comunidad moral, reunida en los concejos locales y representada por los cabezas de familia, la que movilizaba a los voluntarios en respuesta a unos hechos que venían determinados desde fuera con el fin de evitar males mayores y como medida defensiva de la comunidad, ya que los alistados fueron estacionados en el municipio para repeler las incursiones y pudieron recibir la asistencia y visitas de sus familiares durante el verano de aquel año ${ }^{35}$.

No faltaron casos en los que la fidelidad personal pesó de manera determinante a la hora de tomar la decisión de empuñar las armas. En el municipio de Aramayona, que quedó en la zona republicana, como todo el norte de la provincia, después de la detención y el asesinato por las milicias republicanas del dirigente carlista local Basilio Lasaga el 27 de agosto de 1936, su criado, Antonio García Izquierdo, huyó a Vitoria, alistándose como requeté. En este caso, su lealtad hacía la familia Lasaga era total, ya que al quedarse huérfano, la esposa de Basilio le había criado desde niño, formando parte de la familia extensa de los Lasaga ${ }^{36}$.

A su vez, también fue fundamental en la movilización rural la propia división de las comunidades en lo que Javier Ugarte ha denominado banderías, grupos vecinales enfrentados y movidos por lealtades más personales que políticas. En aquel mundo rural, lo verdaderamente importante eran las lealtades e influencias personales, la simpatía, la antipatía, lo moralmente aceptado, la familia, y los círculos locales de solidaridad, comunidad y sociabilidad, mucho más que unas ideas políticas claramente definidas o una identidad de clase o individual, que sí podían estar presentes en los grandes núcleos de población ${ }^{37}$.

Sólo de esta manera se entendería, por ejemplo, el que en la localidad de Barambio, el jovencísimo José Ramón Isasi, de 19 años, consiguiera organizar durante la primavera de 1936 un grupo armado de 30 vecinos, en el que muchos de ellos le doblaban la edad. Esta movilización y su liderazgo se explicarían por el prestigio e influencia de la familia Isasi. El padre de José Ramón, Juan José Isasi, era un comerciante de la localidad a quien acudían los jóvenes de la localidad para conseguir trabajo y los años anteriores había sido propagandista del carlismo.

\footnotetext{
34 Archivo del Territorio Histórico de Álava. (ATHA). DAIC. 12692-A; Ugarte Tellería, Javier, La nueva, op. cit., págs. 119-128.

35 Archivo Municipal de Arrazúa-Ubarrundia. C. 18-3; Ugarte Tellería, Javier, La nueva, op. cit., págs. 132-133.

36 Archivo General Militar de Ávila. (AGMAV). Caja. 5454. Carpeta. 9; Centro Documental de la Memoria Histórica. Causa General de Álava. 1337. Pieza 1a; el concepto de familia extensa en Ugarte Tellería, Javier. La nueva, op. cit., págs. 13 y 113-114.

${ }^{37}$ Ugarte Tellería, Javier, "El carlismo hacia los años 30 del siglo XX. Un fenómeno señal", Ayer, 38, 2000, págs. 158 159.
} 
Se podría decir que su hijo cogió el testigo como "jefe" de la familia al fallecer Juan José en enero de 1936 y movilizó a sus clientelas, ya que no importaban unas siglas o un discurso político lejano y más o menos complejo, sino los lazos de su líder o patrón con ellos y la situación local de enfrentamiento, fuera personal o político, ya que éstas eran las razones últimas que determinaban su movilización. Este era el caso, por ejemplo, de los tres hermanos Marigorta Yarritu, pertenecientes al grupo de Isasi, que habían mantenido incidentes y agresiones con otra rama de la familia que había optado políticamente por el nacionalismo vasco ${ }^{38}$.

En aquella sociedad rural basada en el patronazgo y la clientela, los fuertes lazos y vínculos sociales y familiares que unían a las diferentes comunidades, sin olvidar las fuertemente enraizadas creencias religiosas y el miedo a que una hipotética revolución les quitara sus tierras y animales, hicieron que se creara un caldo de cultivo propicio que posibilitó la fuerte movilización antirrepublicana del Requeté, que superó las previsiones de sus organizadores y consiguió el mayor contingente de voluntarios, 2.131, para apoyar la sublevación en la provincia ${ }^{39}$.

\section{Análisis del voluntariado alavés}

Socio-profesionalmente, la mayoría de los requetés provenían del mundo rural y vivían de la agricultura, la misma base social del carlismo alavés durante la República. Sin embargo, en sus fichas de alistamiento y hojas de servicios manifestaban de manera muy genérica que sus ocupaciones eran las de "labrador" o "jornalero", las cuales pueden reflejar situaciones muy dispares. Por ello, para acercarme más detenidamente a sus perfiles, me he valido de los expedientes de los subsidios que se otorgaron a las familias de los voluntarios, pudiendo estudiar la situación de 517 familias de requetés repartidas por toda la provincia ${ }^{40}$.

\section{ORIGEN SOCIO-PROFESIONAL DE LOS REQUETÉS ALAVESES}

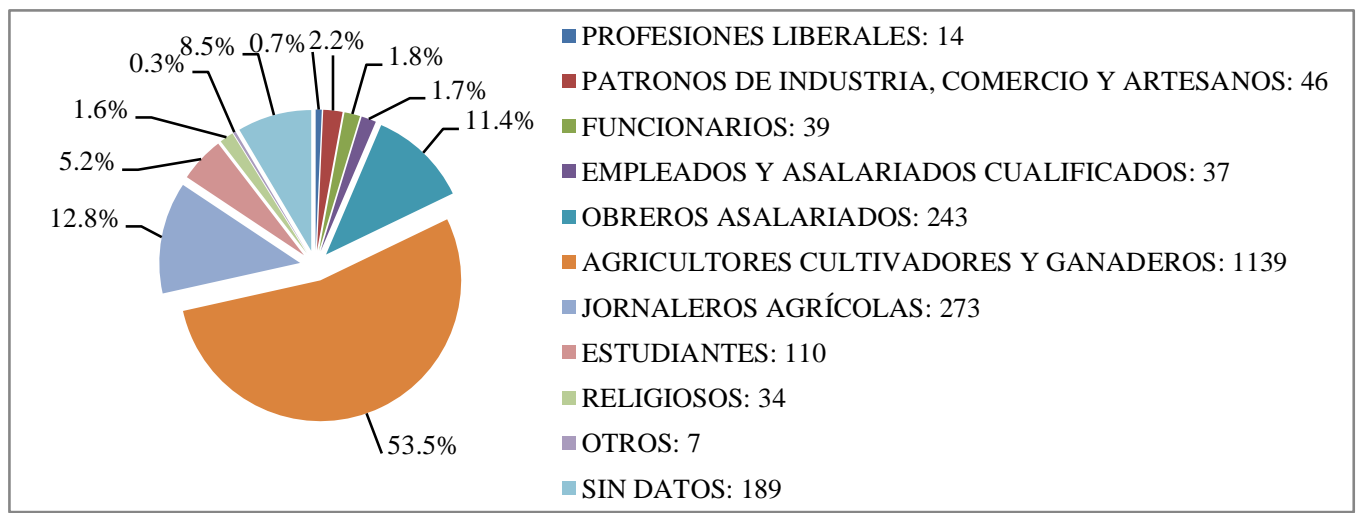

\footnotetext{
${ }^{38}$ Incidentes y rivalidades locales entre los Isasi y los nacionalistas locales en La guerra civil, op. cit., págs. 302-303 y 395; PA. Vitoria. 5-VI-1933; 10-IV-1934; 2-I-1936; LL. Vitoria. 3-VI-1933; 30-XI-1933; el incidente de los Marigorta en $P A$. Vitoria. 2-XII-1935; la formación del grupo en ATHA. DAIC. 12692-A.

${ }^{39} \mathrm{El}$ reclutamiento de voluntarios en otras milicias y el ejército fueron bastante menores en número: 515 en Falange Española, 97 en Acción Popular y 319 en el Ejército.

40ATHA. DH. 50-1 y DAIC. 5395, 5396, 5397 y 5398.
} 


\section{CARACTERÍSTICAS SOCIO-LABORALES DE LOS "JORNALEROS" Y "LABRADORES" DEL REQUETÉ ALAVÉS}

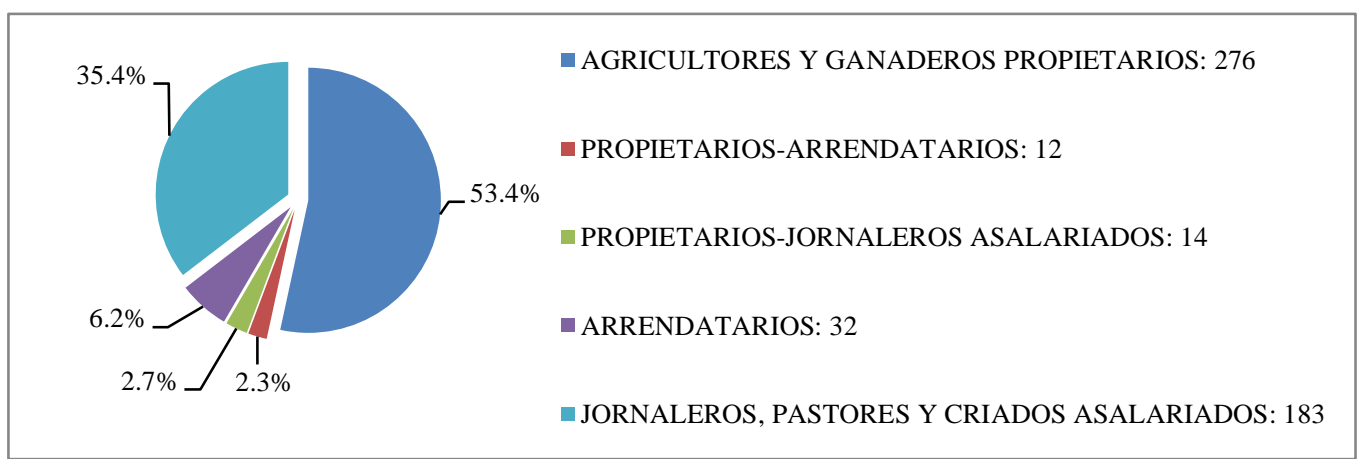

De los datos expuestos se puede deducir que no parece que hubiera un sector dentro del mundo agrícola que destacara sobre los otros. Por un lado, un número alto de asalariados agrícolas provenientes del sur de la provincia, la comarca de Rioja Alavesa, caracterizada por la viticultura y propiedades agrícolas de mayor extensión que la media, mientras que en el resto de la provincia prevalecen los pequeños y medianos propietarios, con algunas familias que debían complementar sus ingresos vendiendo su fuerza de trabajo o arrendando fincas ajenas. Todo ello es coincidente con el hecho de que Álava era una provincia con la propiedad agrícola bastante repartida. Tal y como expresaba el Gobierno Civil en su memoria provincial de $1938^{41}$ :

"La tierra alavesa está muy parcelada. No existe el latifundio ni (...) la mediana propiedad. Existe en cambio el exceso de parcelación del microfundio. La explotación de la tierra es familiar. Cada familia labradora cultiva por si una extensión de tierra variable según la comarca pero que en promedio se puede cifrar en unas 10 o 12 hectáreas. Estas hectáreas son ordinariamente la superficie de 30 o 40 (...) parcelas pequeñas diseminadas.

"Jornaleros campesinos que vivan todo el año a jornal apenas hay sino en los pueblos de la Rioja Alavesa. Y aún allí raro es el que no cultiva alguna tierra por su cuenta. En el resto de la provincia el tipo casi único de obrero del campo es el criado del labrador, soltero, ajustado por año o por temporada y que convive con la familia de su patrono."

En este sentido, las diferentes características geográficas y climáticas de la provincia hacían que hubiera un campesinado heterogéneo en cuanto al tipo de explotación agraria, pero de vida más o menos desahogada ${ }^{42}$ :

"La provincia de Álava no es industrial. En su casi totalidad es agrícola aún con diversos caracteres.- Hay zonas totalmente distintas dentro de estas características. Zona de la llanada: cerealista. Zona de la Montaña, su principal riqueza es el monte. Zona vitivinícola: la Rioja. (...). No obstante, el labrador alavés no es solo cerealista, ni ganadero, sino que extiende sus actividades a un poco de todo, pues propietarios los ayuntamientos y los pueblos de sus montes comunales, tienen ganado y recursos forestales, con que se proveen no solo para sus necesidades domésticas, sino que les sirve para la venta. Puede decirse sin hipérbole, que la vida del labrador en su mayoría propietario o arrendatario, se desenvuelve sin grandes agobios."

\footnotetext{
41 Archivo General de la Administración. (AGA). C. 44/2790.

42 AGA. C. 44/3115; Ugarte Tellería, Javier, La nueva, op. cit. págs. 372-373.
} 
Lo que uniría a todos ellos, por encima de sus diferentes situaciones socioeconómicas, eran sus firmemente arraigadas convicciones religiosas. El propio Devocionario del Requeté lo dejaba claro: "Considérate soldado de una cruzada que pone a Dios como fin y en El confía el triunfo" "43. Las Ordenanzas del Requeté reiteraban el carácter católico de sus integrantes ${ }^{44}$ :

"La fe fundamenta todas las virtudes del soldado «Boina Roja».

Refuerza el espíritu, necesario a tu azarosa vida, con el culto a Dios.

Sírvele siempre.

Muere por Él, que morir así, es vivir eternamente.

Ante Dios nunca serás héroe anónimo.

La Tradición habla a tu alma, purifica tus sentimientos y te acerca a Dios. Ella enseña a amar a la Iglesia.

Sé siempre católico práctico, con conocimiento claro de lo que Dios desea para servirle, que es el fin esencial.

Tú, soldado de la Tradición, habrás de tener puesto en el Reino de Dios.”

A estos agricultores y jornaleros habría que añadir otros oficios artesanales como herreros, carpinteros, etcétera, lo que nos da un peso rural sobrerrepresentado en la movilización antirrepublicana, ya que, contando todo el voluntariado provincial, representa el $80 \%$ de este, mientras que el $65 \%$ de la población alavesa vivía fuera del casco urbano de Vitoria. En este sentido, el peso de lo rural es abrumador en los requetés, proviniendo el $90 \%$ de ellos de ese ámbito, originarios sobre todo de las comarcas de Rioja y Valles Alaveses, donde el nacionalismo vasco no estaba implantado y no disputaba al carlismo su base social. Tal y como afirmaba la propaganda del carlismo, era el mundo rural idealizado, "sano" ideológicamente, el que había tomado sobre sí el peso de la movilización contrarrevolucionaria frente al corrupto mundo urbano, al que habían llegado ideas nuevas tan perniciosas como el laicismo, el comunismo, etcétera ${ }^{45}$ :

\begin{abstract}
"Aires de la calle. Aromas de la aldea, que son aromas de España. Ahí ves, lector, desfilar al hombre de España, al que España quiere con cariños de madre. En su marcialidad no muy seguros, pero en su bravura y decisión estos hombres que aquí ves, lector son estampa de la reciedumbre española. Aventajan en eficiencia al señoritillo vicioso y podrido de la urbe. El agro alavés sano y honrado ha vencido en buena lid a la frivolidad y a la vida ciudadana fácil y mendosa."
\end{abstract}

En cuanto a los sectores urbanos vitorianos que se alistaron en el Requeté, estos provinieron mayoritariamente de los círculos de obreros y artesanos católicos, cuya cuarte parte, además, había nacido en los pueblos de la provincia y habían emigrado a Vitoria. También aparecen los escasos representantes de las familias de clase media-alta que militaban en el carlismo, ya que los jóvenes provenientes de esos ámbitos, por lo general, prefirieron alistarse en Acción Popular y Falange Española ${ }^{46}$.

\footnotetext{
${ }^{43}$ Devocionario del Requeté, Palencia, Imprenta del Diario Palentino, 1936.

${ }^{44}$ Ordenanza del Requeté, Vigo, Imprenta Rápida, 1936.

${ }^{45}$ García de Albéniz, Felipe, Álava, op. cit., pág. 30.

46 Acción Popular era la marca electoral de la CEDA en Álava, con unos afiliados y electorado provenientes de las clases medias y altas conservadoras vitorianas y aunque formó una milicia propia no tuvo un gran éxito movilizador, mientras que Falange Española, el partido fascista español, se nutría de personas muy jóvenes sin una militancia política
} 
También hay que tener en cuenta el papel que los lazos familiares jugaron en el alistamiento, ya que se enrolaron voluntarios 466 hermanos en el Requeté, un 21,8 \% del total. A ellos habría que añadir, excepcionalmente, casos del alistamiento de padre e hijo, muy utilizados por la propaganda, literatura y el imaginario colectivo del carlismo, como los de Gregorio y Moisés Gil de Labastida, de 47 y 18 años respectivamente, y el de familiares de segundo grado, más difíciles de rastrear, pero que, muy probablemente, también debieron abundar ${ }^{47}$. En este sentido, una de las principales razones de la pervivencia del carlismo desde el siglo XIX habría que buscarla en el marco familiar como "espacio esencial de transmisión de lo político, de forma explícita o implícitamente. Era, en definitiva, la base de la socialización política" en el que abuelos, padres, hermanos, tíos, vecinos y madres aseguraron su continuidad mediante la educación dada en el hogar, el relato familiar más o menos mítico, etcétera. ${ }^{48}$ Por ello, el recuerdo de las pasadas guerras civiles del siglo XIX era importantísimo dentro de los requetés y el carlismo. Por ejemplo, en su Ordenanza, se dejaba claro que eran los descendientes de un pasado lleno de gloria ${ }^{49}$ :

"Procedes de la elección entre los afiliados a la Comunión Tradicionalista.

Eres, por tanto, orgullo y heredero de tus gloriosos antepasados.

Te llamas "Boina Roja", porque eres soldado selecto, entusiasta, leal, y la Tradición tiene en ti el más firme y valioso sostén.

Examina tu misión, recuerda viejas glorias, y verás como el pensamiento que te rige y el sentimiento que te anima, constituyen la substantividad que informó la existencia y origen de la España Inmortal."

Políticamente, el Requeté se nutrió de personas provenientes en su mayor parte del carlismo. Si bien la mayoría no parece que hubiera militado de carnet, sí que nos encontramos con que muchos de los que se alistaron, de una u otra manera estaban vinculados a él, como por ejemplo hijos de alcaldes y concejales carlistas. También nos encontramos a afiliados a organizaciones afines, como la Casa Social Católica de Vitoria, sindicato católico afín a Hermandad Alavesa, o la Asociación de Estudiantes Tradicionalistas. De ahí que fuera un voluntariado muy monolítico ideológicamente, mientras que quienes se alistaron para conseguir refugio por una militancia política izquierdista o nacionalista vasca durante los años anteriores fueron muy escasos. Hasta donde he podido averiguar, sólo el 2,4 \% de los alistados en el Requeté tenía esa procedencia, y sólo existe constancia de un desertor por causas ideológicas, el anarquista Manuel Ruiz, alistado como requeté en agosto de 1936, que se pasó a filas republicanas en enero del año siguiente ${ }^{50}$.

Con respecto a la estructura de edad de los requetés, observar que la mayoría son personas jóvenes, con una media de edad de 23,5 años, aunque es muy llamativo el hecho de que bastantes personas de edad madura, en muchos casos casados y con hijos, un $8 \%$ del total, se alistaran y combatieran, como por ejemplo Luciano López de Echezarreta, vecino de Yécora, de 35 años y padre de 6 hijos y con su esposa embarazada del séptimo, voluntario desde el 19 de julio de $1936^{51}$. Esto puede dar idea de la solidez de sus convicciones y de cómo el alistarse y combatir contra la República fue una cuestión en la que la religión jugaba un papel primordial al sentirse atacados en sus más profundas creencias durante los años anteriores.

anterior, provenientes sobre todo de las clases medias y altas urbanas y, aunque consiguió un relativo éxito movilizador, no consiguió igualar al Requeté. Ruiz Llano, Germán, Álava, op. cit., págs. 86-111.

${ }^{47}$ Canal, Jordi. Banderas, op. cit., págs. 237-274; Blinkhorn, Martin, Carlismo, op. cit., págs. 359-360; el alistamiento de los Gil en ATHA. DH. 50.

${ }^{48}$ Canal, Jordi, Banderas, op. cit., pág. 249.

${ }^{49}$ Ordenanza, op. cit., pág. 8.

50 AGMAV. Jefatura de Milicias de Vitoria. Legajo Fusilados, Desertores y Procesados.

51 ATHA. DH. 5396. 


\section{ESTRUCTURA DE EDAD DEL REQUETÉ ALAVÉS}

\begin{tabular}{|c|c|c|c|}
\hline EDAD & & & \\
\hline $46-\ldots$ & $0,8 \%$ & & \\
\hline $41-45$ & $1,5 \%$ & & \\
\hline $36-40$ & $2,5 \%$ & & \\
\hline $31-35$ & $6,1 \%$ & & \\
\hline $26-30$ & & $\begin{array}{c}18,8 \\
\%\end{array}$ & \\
\hline $21-25$ & & & $30,1 \%$ \\
\hline $16-20$ & & & $32,4 \%$ \\
\hline$\ldots-15$ & $1 \%$ & & \\
\hline
\end{tabular}

En este sentido, la importancia de la religión como factor de movilización fue enorme, ya que Álava era una provincia donde el catolicismo formaba parte de las creencias y las costumbres sociales y culturales más arraigadas de su población. Por ejemplo, Idearium, la revista del Seminario de Vitoria, realizó una encuesta a los sacerdotes de varios pueblos de la provincia durante los años 1934-1935 sobre el cumplimiento de las prácticas religiosas en las localidades en las que ejercían su labor pastoral. En general, estos comentaban que la casi totalidad de la población cumplía con fervor y regularidad sus deberes religiosos y la única inquietud venía dada por las posibles influencias de las costumbres de la ciudad ${ }^{52}$. Así comentaba Domingo Jakakortajarena, párroco del pueblo de Nafarrate, la llegada de nuevas ideas provenientes de las zonas rurales e industriales, su influencia en la religiosidad y la inquietud que le provocaban ${ }^{53}$ :

"Las seis familias de Nafarrate, eran buenos cristianos (...) y vivían allí mismo todos de la agricultura, pero el hijo mayor de una familia, trabajaba en una fábrica (...) y allí se convirtió en un revolucionario rojo y casi todos los sábados y en plan de descanso (...) venía a casa, hacía propaganda para conquistar entre los jóvenes algunos adeptos. Debió convencer a dos hermanos de su casa, porque no me venían más a Misa. (...) Me causaba gran dolor y profunda tristeza el que me fuera llevando por el mal camino a tan buenos chicos y no sabía qué hacer."

Al respecto, el papel del clero más integrista fue también muy importante como elemento legitimador de la movilización, animando a los mozos de los pueblos a alistarse como voluntarios o tomando ellos mismos las armas, como Juan Miguel Tapia, párroco de la localidad de Bernedo, que el 25 de julio de 1936 "desfiló con los requetés por las calles de Vitoria vestido de sotana, boina roja con borla morada en la cabeza y pistola en bandolera" 54 .

La movilización del Requeté y el mundo rural contrastó a los ojos de los militares sublevados con Vitoria, considerada fría y apática por el escaso número de voluntarios que aportaba y la escasa calidez con que acogía las manifestaciones callejeras de los partidarios de la sublevación. Si bien en la provincia había prevalecido en general el entusiasmo del Requeté, Vitoria era una decepción.

\footnotetext{
${ }^{52}$ Idearium. Vitoria. Números 3, 4, 5 y 6; Pablo, Santiago de, Goñi, Joseba y López de Maturana, Virginia, La Diócesis de Vitoria, 150 años de Historia (1862-2012), Vitoria, ESET, 2013, págs. 263-264.

${ }^{53}$ Iakakortajarena, Txomin, Dos ideales en la vida, Vitoria, Seminario de Vitoria, 1993, pág. 145.

${ }^{54}$ La guerra civil, op. cit., pág. 290.
} 
Pocos días después de la proclamación del estado de guerra, el 25 de julio de 1936, día de Santiago, tradicionalmente de fiesta y mercado en Vitoria, se intentó y fracasó una tentativa de movilizar a la ciudad, a pesar de la parafernalia religiosa, propagandística y de desfiles a que dio lugar ${ }^{55}$. Expresaba el coronel Fernández Ichaso su decepción días después ${ }^{56}$ :

"Es lamentable; pero es así y así hay que decirlo. Vitoria está dando una sensación de tibieza que contrasta con todo el resto de España. (...). España entera está vibrando en estos momentos al impulso de un sentimiento patriótico admirable. Este sentimiento patriótico debe animar a Vitoria, ciudad privilegiada, que gracias a Dios no sufre rigores de ninguna especie y vive -en estas horas de inquietud- la vida plácida de los tiempos normales."

Lo que ocurría es que se trataba de una ciudad en la que la modernidad y la industrialización se dejaban sentir. En febrero de 1936, el FP había ganado las elecciones en la ciudad, aunque gracias a la desunión de las candidaturas derechistas, siendo considerable el peso de los partidos y sindicatos de izquierdas. A ello habría que añadir la escasa conflictividad político-social anterior a la contienda, con lo cual la convivencia vecinal no se había visto alterada de manera grave. Todo ello lleva a pensar que es posible que muchos derechistas y conservadores moderados creyeran que no había motivos para una movilización de carácter violento y que, con la proclamación del estado de guerra, bastaba para mantener el orden público y social y el vitorianismo.

El vitorianismo sería la expresión de una fortísima identidad colectiva de la ciudad mediante un discurso creado, idealizado y fomentado por las clases altas locales, tanto de derechas y de izquierdas, que desde el siglo XIX servía de aglutinante interno. Según esta manera de verse a sí misma, en Vitoria, debido a las "buenas maneras" de su vecindario, prevalecía la unión y cordialidad de todos, frente a lo malo, en este caso la violencia y la guerra, mientras que, en anteriores épocas de turbulencias, con huelgas, disturbios, etcétera, el peligro se achacaba a personas y entes ajenos a la ciudad. Por otro lado, esta misma cultura local creó un sentimiento de dicotomía urbano-rural que podría rastrearse desde el siglo XIX, con los enfrentamientos entre carlistas y liberales, por la cual, lo rústico y pueblerino, el Requeté en este caso, era rechazado como algo que se podía identificar con el atraso. Mientras que las cuestiones modernas y cosmopolitas, como las nuevas tecnologías o las vanguardias culturales, eran las que prevalecían en Vitoria. De ahí el escaso entusiasmo de los habitantes urbanos por el Requeté, en contraste con el mundo rural tradicional, y la mayor atracción que podían tener las más novedosas y modernas doctrinas de Falange y Acción Popular sobre los hijos de las familias de las clases altas y medias urbanas ${ }^{57}$.

Se puede decir que la movilización de los requetés fue indispensable por su fiabilidad, disciplina y motivación para que la sublevación no acabara en un fracaso total, ya que una vez armados y organizados ayudaron de manera inestimable a las unidades militares insurrectas a hacer frente a las milicias republicanas. En el caso de Álava, en aquellos primeros y decisivos momentos de julio de 1936, sus requetés, junto a los milicianos falangistas y de Acción Popular, ayudaron a consolidar el control de los militares en Vitoria, neutralizaron a los posibles oponentes, ayudaron a establecer un frente en el norte de la provincia frenando a las milicias vizcaínas y enviaron rápidamente refuerzos a las fuerzas enviadas al frente de Madrid.

\section{A modo de conclusión}

El apoyo mayoritario del campesinado tradicional alavés a la sublevación militar se forjó en buena medida a través del miedo a una posible revolución comunista que acabara con sus propiedades,

\footnotetext{
${ }^{55}$ PA y LL. Vitoria. 25-VII-1936; Ugarte Tellería, Javier, La nueva, op. cit., págs. 204-205.

${ }^{56} \mathrm{PA}$. Vitoria. 4-VIII-1936.

${ }^{57}$ Rivera, Antonio, La conciencia histórica de una ciudad "El Vitorianismo", Vitoria, Diputación Foral de Álava, 1990; Ugarte Tellería, Javier. La nueva, op. cit., págs. 206-227.
} 
creencias y modos de vida. Las percepciones del peligro revolucionario durante los años republicanos se vieron acentuadas por dos cuestiones fundamentales: la primera fue el rebrote de las luchas sociales, fruto de la crisis económica que había comenzado en 1929, el resurgir del movimiento obrero y la intransigencia de la CNT para con el régimen republicano, realizando el sindicato anarquista numerosas huelgas, sabotajes y violencias que alentaron a las derechas a presentar al régimen republicano como débil e inoperante frente a los desórdenes; la segunda fue la cuestión religiosa y la laicidad que defendía el nuevo régimen. Por un lado, las estridencias, más por la procacidad de su lenguaje que por los hechos, de los republicanos más anticlericales de la provincia; por otro, el modo en que las diferentes medidas y leyes de tipo laico se fueron implementando en la provincia por unas autoridades que no destacaron por su tacto a la hora de ponerlas en práctica, motivaron el descontento y la resistencia de la mayoría de la población alavesa, fervientemente católica, sintiéndose atacada en lo más hondo de sus creencias. Eso llevó a que la República se enajenara su inicial simpatía, buena imagen y expectativas de la mayoría de la población, tal y como demuestran los resultados de las elecciones de junio 1931, ganadas por primera y única vez por un candidato republicano durante aquel período ${ }^{58}$.

El resultado fue que amplios sectores de la población comenzaron a identificar a la República con las izquierdas anticatólicas, derivando en una radicalización de los creyentes frente al régimen republicano, visto progresivamente como la antesala de una revolución social que ya "había llegado" a la provincia tras el fallido alzamiento anarquista de Labastida de 1933. Se acrecentó así el miedo a los desórdenes, quemas de edificios religiosos, expropiación y colectivización de la propiedad, etcétera. En este sentido, es interesante observar cómo en las elecciones a Cortes de noviembre de 1933 se produjo un vuelco electoral en la provincia con respecto a las de junio de 1931. En aquella ocasión la izquierda alavesa quedó en situación marginal, resultando, por el contrario, elegidos dos candidatos católicos, el carlista Oriol y el nacionalista vasco Landáburu.

En este contexto, el triunfo electoral del FP en febrero de 1936 acrecentó esos temores y los preparativos para una solución de fuerza por parte de aquellos sectores que, como el carlismo, nunca aceptaron la legitimidad de la República y conspiraron contra ella desde un principio.

La sublevación militar de julio de 1936 triunfó fácilmente en Álava, obteniendo los militares alzados el apoyo de la mayoría de la población rural, puesto que Vitoria, el único núcleo urbano de la provincia y donde la modernización social y económica habían llegado a calar, se movía, debido al vitorianismo -la peculiar cultura localista de la ciudad- en unas coordinadas identitarias diferentes. La capital se veía a sí misma como un remanso de paz y cordialidad frente a los odios que se habían desatado en el exterior, sin oponerse a los sublevados, pero tampoco arropándoles de la manera masiva que esperaban.

En conclusión, en una sociedad como la alavesa, mayoritariamente rural y católica, los sublevados encontraron un semillero de combatientes y apoyos frente a lo que era visto como un peligro por esta, la Revolución: identificada con la llegada de nuevas ideas que comenzaban a prender: laicismo, socialismo, comunismo, democracia, etcétera. Todo ello chocaba con lo establecido tradicionalmente, provocando tensiones sociales que no eran exclusivas de aquella sociedad, sino de todo Europa. Esa movilización, junto a la de las clases medias y altas urbanas conservadoras, que veían en peligro su preeminencia e intereses sociales y económicos, y la de la Iglesia, que veía contestado su dominio cultural e ideológico, todos bajo el mando de unos militares autoproclamados intérpretes de la voluntad nacional, hicieron posible la movilización contrarrevolucionaria de Álava de julio de 1936, contribuyendo a la victoria de los sublevados y al establecimiento de una dictadura que iba a durar hasta 1975.

\footnotetext{
58 Pablo, Santiago de, La Segunda, op. cit., págs. 118-126.

59 Pablo, Santiago de, La Segunda, op. cit., págs. 183-203.
} 


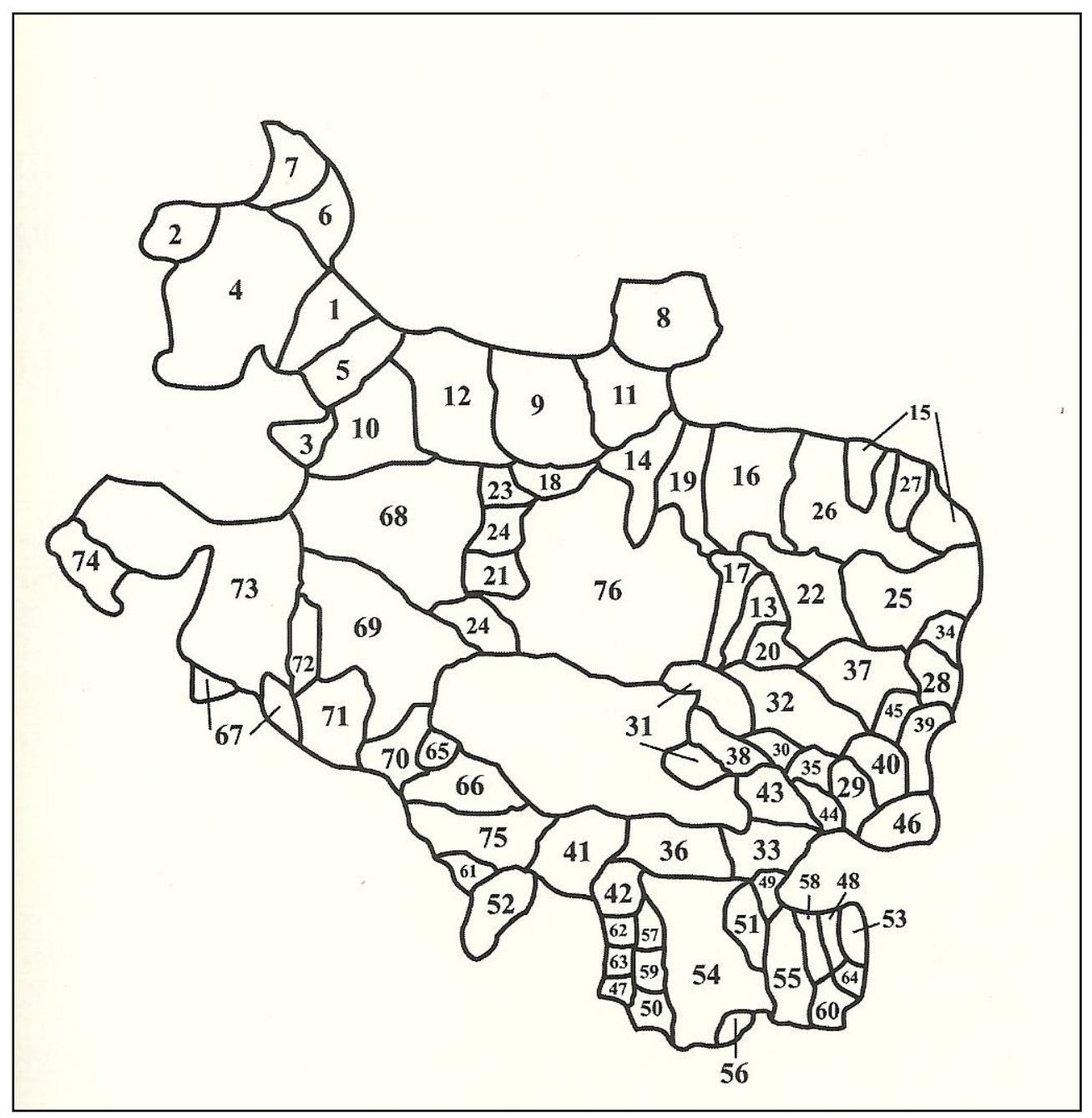


ANEXO 2. ALAVESES ALISTADO VOLUNTARIAMENTE EN EL REQUETÉ

PROVINCIA

\begin{tabular}{|c|c|}
\hline REQUETÉS & $\begin{array}{c}\text { \% POBLACIÓN } \\
\text { MASCULINA }\end{array}$ \\
\hline 2.131 & 4,3 \\
\hline
\end{tabular}

COMARCAS

\begin{tabular}{|c|c|c|}
\cline { 2 - 3 } \multicolumn{1}{c|}{} & REQUETÉS & $\%$ \\
\hline CUENCA CANTÁBRICA ${ }^{00}$ & 211 & \\
\hline ESTRIBACIONES DEL GORBEA & 187 & 3,5 \\
\hline LLANADA ALAVESA & 226 & 3,2 \\
\hline MONTAÑA ALAVESA & 181 & 4,6 \\
\hline RIOJA ALAVESA & 479 & 7,7 \\
\hline VALLES ALAVESES & 504 & 11,7 \\
\hline VITORIA & 343 & 1,7 \\
\hline
\end{tabular}

MUNICIPIOS

\section{CUENCA CANTÁBRICA}

\begin{tabular}{|c|c|c|c|}
\hline $\begin{array}{c}\mathrm{N}^{\circ} \\
\text { MAPA }\end{array}$ & MUNICIPIOS & REQUETÉS & $\%$ \\
\hline 1 & AMURRIO & 11 & 1,3 \\
\hline 2 & ARCENIEGA & 9 & 1,4 \\
\hline 3 & ARRASTARIA & 40 & 11,7 \\
\hline 4 & AYALA & 55 & 3,7 \\
\hline 5 & LEZAMA & 11 & 1,5 \\
\hline 6 & LLODIO & 74 & 5,1 \\
\hline 7 & OQUENDO & 11 & 2,6 \\
\hline
\end{tabular}

ESTRIBACIONES DEL GORBEA

\begin{tabular}{|c|c|c|c|}
\hline $\begin{array}{c}\mathrm{N}^{\circ} \\
\text { MAPA }\end{array}$ & MUNICIPIOS & REQUETÉS & $\%$ \\
\hline 8 & ARAMAYONA $^{61}$ & 29 & 3,2 \\
\hline 9 & CIGOITIA & 28 & 4,3 \\
\hline 10 & URCABUSTAIZ & 55 & 8,1 \\
\hline 11 & VILLARREAL & 30 & 4,5 \\
\hline 12 & ZUYA & 45 & 4,4 \\
\hline
\end{tabular}

LLANADA ALAVESA

\begin{tabular}{|c|c|c|c|}
\hline $\begin{array}{c}\mathrm{N}^{\circ} \\
\text { MAPA }\end{array}$ & MUNICIPIOS & REQUETÉS & $\%$ \\
\hline 13 & ALEGRIA & 28 & 7,7 \\
\hline 14 & $\begin{array}{c}\text { ARRAZUA- } \\
\text { UBARRUNDIA }\end{array}$ & 21 & 4,1 \\
\hline 15 & ASPARRENA & 22 & 1,9 \\
\hline 16 & BARRUNDIA & 18 & 2,9 \\
\hline 17 & ELBURGO & 3 & 1,1 \\
\hline 18 & FORONDA & 17 & 3,5 \\
\hline 19 & GAMBOA & 12 & 3 \\
\hline 20 & GAUNA & 5 & 3,1 \\
\hline 21 & IRUÑ & 7 & 3,9 \\
\hline 22 & IRURAIZ & 13 & 3,2 \\
\hline
\end{tabular}

${ }^{60}$ Esta comarca quedó en su totalidad en zona republicana de julio de 1936 a junio de 1937.

${ }^{61}$ Este municipio quedó en zona republicana de julio de 1936 a abril de 1937. 


\begin{tabular}{|c|c|c|c|}
\hline 23 & LOS HUETOS & 4 & 3 \\
\hline 24 & MENDOZA & 2 & 1,3 \\
\hline 25 & $\begin{array}{c}\text { NANCLARES } \\
\text { DE LA OCA }\end{array}$ & 29 & 5,6 \\
\hline 25 & SALVATIERRA & 17 & 2 \\
\hline 26 & SAN MILLAN & 28 & 3,1 \\
\hline 27 & ZALDUENDO & 0 & 0 \\
\hline
\end{tabular}

MONTAÑA ALAVESA

\begin{tabular}{|c|c|c|c|}
\hline $\begin{array}{c}\mathrm{N}^{\circ} \\
\mathrm{MAPA}\end{array}$ & MUNICIPIOS & REQUETÉS & $\%$ \\
\hline 28 & $\overline{\text { ALDA }}$ & 12 & 7,9 \\
\hline 29 & ANTOÑANA & 15 & 7 \\
\hline 30 & APELLANIZ & 9 & 7,2 \\
\hline 31 & ARLUCEA & 8 & 4,6 \\
\hline 32 & ARRAYA & 6 & 1,3 \\
\hline 33 & BERNEDO & 20 & 6,7 \\
\hline 34 & CONTRASTA & 5 & 4,5 \\
\hline 35 & CORRES & 1 & 5,9 \\
\hline 36 & LAGRÁN & 16 & 5,6 \\
\hline 37 & LAMINORIA & 3 & 1,5 \\
\hline 38 & MARQUINEZ & 5 & 3,1 \\
\hline 39 & ORBISO & 2 & 1,3 \\
\hline 40 & OTEO & 3 & 4,8 \\
\hline 41 & PEÑACERRADA & 33 & 7,9 \\
\hline 42 & PIPAON & 7 & 6,8 \\
\hline 43 & QUINTANA & 6 & 6,9 \\
\hline 44 & $\begin{array}{l}\text { SAN ROMÁN } \\
\text { DE CAMPEZO }\end{array}$ & 2 & 4,9 \\
\hline 45 & $\begin{array}{l}\text { SAN VICENTE } \\
\text { DE ARANA }\end{array}$ & 1 & 1 \\
\hline 46 & $\begin{array}{l}\text { SANTA CRUZ } \\
\text { DE CAMPEZO }\end{array}$ & 27 & 4,7 \\
\hline
\end{tabular}

RIOJA ALAVESA

\begin{tabular}{|c|c|c|c|}
\hline $\begin{array}{c}\mathrm{N}^{\circ} \\
\text { MAPA }\end{array}$ & MUNICIPIOS & REQUETÉS & $\%$ \\
\hline 47 & $\begin{array}{c}\text { BAÑOS DE } \\
\text { EBRO }\end{array}$ & 15 & 6,7 \\
\hline 48 & BARRIOBUSTO & 21 & 11,3 \\
\hline 49 & CRIPÁN & 11 & 9 \\
\hline 50 & ELCIEGO & 39 & 5,6 \\
\hline 51 & ELVILLAR & 25 & 8,5 \\
\hline 52 & LABASTIDA & 64 & 12 \\
\hline 53 & LABRAZA & 7 & 6 \\
\hline 54 & LAGUARDIA & 90 & 7,9 \\
\hline 55 & LANCIEGO & 25 & 5,6 \\
\hline 56 & $\begin{array}{l}\text { LAPUEBLA DE } \\
\text { LABARCA }\end{array}$ & 28 & 6,8 \\
\hline 57 & LEZA & 0 & 0 \\
\hline 58 & MOREDA & 46 & 14,6 \\
\hline 59 & NAVARIDAS & 3 & 2,4 \\
\hline 60 & OYÓN & 29 & 5,2 \\
\hline 61 & $\begin{array}{l}\text { SALINILLAS DE } \\
\text { BURADÓN }\end{array}$ & 19 & 7,9 \\
\hline 62 & SAMANIEGO & 5 & 3,3 \\
\hline 63 & VILLABUENA & 12 & 6,6 \\
\hline 64 & YÉCORA & 40 & 13,2 \\
\hline
\end{tabular}

VALLES ALAVESES

\begin{tabular}{|c|c|c|c|}
\hline $\begin{array}{c}\mathrm{N}^{\circ} \\
\text { MAPA }\end{array}$ & MUNICIPIOS & REQUETÉS & $\%$ \\
& & & \\
\hline 65 & ARMIÑON & 27 & 11,8 \\
\hline
\end{tabular}


Contenciosa, Año V, nro.7, 2017 - ISSN 2347-0011

Dossier La Guerra Civil española: nuevas miradas, perspectivas y lineas de investigación

\begin{tabular}{|c|c|c|c|}
\hline 66 & BERANTEVILLA & 77 & 16,1 \\
\hline 67 & BERGUENDA & 31 & 7,8 \\
\hline 68 & CUARTANGO & 23 & 5,2 \\
\hline 69 & RIBERA ALTA & 32 & 3,9 \\
\hline 70 & RIBERA BAJA & 25 & 6 \\
\hline 71 & SALCEDO & 45 & 11,7 \\
\hline 72 & $\begin{array}{c}\text { SALINAS DE } \\
\text { AÑANA }\end{array}$ & 23 & 8,4 \\
\hline 73 & VALDEGOVIA & 148 & 9,1 \\
\hline 74 & VALDEREJO & 9 & 6,8 \\
\hline 75 & ZAMBRANA & 64 & 14,3 \\
\hline
\end{tabular}

VITORIA

\begin{tabular}{|c|c|c|c|}
\hline $\begin{array}{c}\mathrm{N}^{\circ} \\
\text { MAPA }\end{array}$ & ZONAS & REQUETÉS & $\%$ \\
\hline 76 & $\begin{array}{c}\text { CASCO } \\
\text { URBANO }\end{array}$ & 242 & 1,4 \\
\hline & PUEBLOS & 101 & 3,6 \\
\hline
\end{tabular}




\section{ANEXO. $\mathbf{N}^{\circ}$ 3. RESULTADOS ELECTORALES DE ÁLAVA EN LAS ELECCIONES DE FEBRERO DE $1936^{62}$}

PROVINCIA

\begin{tabular}{|c|c|c|c|c|c|c|c|c|}
\cline { 2 - 9 } \multicolumn{1}{c|}{} & HA & $\%$ & CEDA & $\%$ & FP & $\%$ & PNV $^{63}$ & $\%$ \\
\hline VOTOS & 16.020 & 37,10 & 8.681 & 20,10 & 9.521 & 22,04 & 8.958 & 20,76 \\
\hline
\end{tabular}

\section{COMARCAS}

\begin{tabular}{|c|c|c|c|c|c|c|c|c|}
\hline & HA & $\%$ & CEDA & $\%$ & FP & $\%$ & PNV & $\%$ \\
\hline CUENCA CANTÁBRICA & 2.406 & 47,6 & 312 & 6,1 & 592 & 11,7 & 1.735 & 34,3 \\
\hline ESTRIBACIONES DEL GORBEA & 1.347 & 42,6 & 220 & 6,9 & 188 & 5,9 & 1.400 & 44,3 \\
\hline LLANADA ALAVESA & 1.652 & 30,8 & 1.407 & 26,6 & 835 & 15,6 & 1.456 & 27,2 \\
\hline VALLES ALAVESES & 2.676 & 58,3 & 648 & 14,1 & 509 & 11,1 & 752 & 16,4 \\
\hline MONTAÑA ALAVESA & 1.012 & 31,4 & 1.111 & 34,4 & 367 & 11,4 & 735 & 22,8 \\
\hline RIOJA ALAVESA & 2.519 & 47,6 & 828 & 15,6 & 1.564 & 29,5 & 379 & 7,1 \\
\hline VITORIA & 4.408 & 26,2 & 4.390 & 26,1 & 5.385 & 32 & 2.502 & 14,8 \\
\hline
\end{tabular}

\section{CUENCA CANTÁBRICA}

\begin{tabular}{|c|c|c|c|c|c|c|c|c|}
\hline & HA & $\%$ & CEDA & $\%$ & FP & $\%$ & PNV & $\%$ \\
\hline AMURRIO & 154 & 22,03 & 180 & 25,75 & 132 & 18,84 & 227 & 32,47 \\
\hline ARCENIEGA & 214 & 45,53 & 19 & 4,04 & 85 & 18,08 & 152 & 32,34 \\
\hline ARRASTARIA & 148 & 58,03 & 6 & 2,3 & 35 & 13,72 & 66 & 25,88 \\
\hline AYALA & 707 & 55,97 & 63 & 4,98 & 119 & 9,42 & 374 & 29,61 \\
\hline LEZAMA & 245 & 39,70 & 17 & 2,75 & 97 & 15,72 & 256 & 41,49 \\
\hline LLODIO & 716 & 53,27 & 14 & 1,04 & 120 & 8,92 & 487 & 36,23 \\
\hline OQUENDO & 222 & 53,11 & 13 & 3,11 & 4 & 0,96 & 177 & 42,34 \\
\hline
\end{tabular}

ESTRIBACIONES DEL GORBEA

\begin{tabular}{|c|c|c|c|c|c|c|c|c|}
\hline & HA & $\%$ & CEDA & $\%$ & FP & $\%$ & PNV & $\%$ \\
\hline ARAMAYONA & 273 & 34,68 & 12 & 1,5 & 15 & 1,9 & 486 & 61,75 \\
\hline CIGOITIA & 301 & 63,36 & 4 & 0,84 & 8 & 0,16 & 161 & 33,89 \\
\hline URCABUSTAIZ & 272 & 49,45 & 95 & 17,27 & 56 & 10,18 & 126 & 22,90 \\
\hline VILLARREAL & 127 & 23,34 & 35 & 6,43 & 108 & 19,85 & 273 & 50,01 \\
\hline ZUUY & 374 & 46,28 & 75 & 9,28 & 1 & 0,12 & 354 & 43,81 \\
\hline
\end{tabular}

\section{LLANADA ALAVESA}

\begin{tabular}{|c|c|c|c|c|c|c|c|c|}
\hline & HA & $\%$ & CEDA & $\%$ & FP & $\%$ & PNV & $\%$ \\
\hline ALEGRIA & 98 & 31,11 & 91 & 28,88 & 84 & 26,66 & 42 & 13,33 \\
\hline ARRAZUA-UBARRUNDIA & 85 & 23,54 & 126 & 34,90 & 46 & 12,74 & 104 & 28,80 \\
\hline ASPARRENA & 37 & 4,66 & 370 & 46,65 & 164 & 20,68 & 217 & 27,36 \\
\hline BARRUNDIA & 216 & 44,60 & 44 & 9,05 & 53 & 10,90 & 172 & 35,45 \\
\hline ELBURGO & 48 & 23,41 & 81 & 39,51 & 23 & 11,21 & 52 & 25,36 \\
\hline FORONDA & 222 & 65,48 & 41 & 12,09 & 41 & 12,09 & 33 & 9,73 \\
\hline GAMBOA & 93 & 33,81 & 69 & 25,09 & 40 & 14,54 & 73 & 26,54 \\
\hline GAUNA & 63 & 45,98 & 7 & 5,10 & 9 & 6,56 & 58 & 42,33 \\
\hline IRUNA & 44 & 34,37 & 6 & 4,68 & 25 & 19,53 & 52 & 40,62 \\
\hline IRURAIZ & 46 & 20 & 91 & 39,56 & 18 & 7,82 & 75 & 32,60 \\
\hline LOS HUETOS & 77 & 62,60 & 7 & 5,69 & 24 & 19,51 & 15 & 12,19 \\
\hline MENDOZA & 35 & 28 & 33 & 26,4 & 22 & 17,6 & 35 & 28 \\
\hline SALCLARES DE LA OCA & 125 & 36,65 & 108 & 31,67 & 82 & 24,04 & 26 & 7,62 \\
\hline SAN MILLAN & 182 & 24,66 & 136 & 18,42 & 101 & 13,68 & 317 & 42,95 \\
\hline ZALDUENDO & 267 & 40,45 & 149 & 22,57 & 69 & 10,45 & 171 & 25,90 \\
\hline
\end{tabular}

MONTAÑA ALAVESA

\begin{tabular}{|c|c|c|c|c|c|c|c|c|}
\hline & HA & $\%$ & CEDA & $\%$ & FP & $\%$ & PNV & $\%$ \\
\hline ALDA & 26 & 20,96 & 65 & 52,41 & 1 & 0,80 & 29 & 23,38 \\
\hline ANTOÑANA & 95 & 49,22 & 65 & 33,67 & 26 & 13,47 & 7 & 3,62 \\
\hline APELLANIZ & 42 & 36,52 & 29 & 25,21 & 17 & 14,78 & 27 & 23,47 \\
\hline ARLUCEA & 61 & 55,45 & 14 & 12,72 & 1 & 0,90 & 34 & 30,90 \\
\hline ARRAYA & 60 & 18,34 & 174 & 53,21 & 64 & 19,57 & 28 & 8,56 \\
\hline
\end{tabular}

${ }^{62}$ Elaboración propia a partir de Pablo, Santiago de, La Segunda, op. cit., págs. 344-345.

${ }^{63}$ Partido Nacionalista Vasco. 


\begin{tabular}{|c|c|c|c|c|c|c|c|c|}
\hline & 66 & 27,16 & 117 & 48,14 & 46 & 18,93 & 14 & 5,76 \\
\hline BERNEDO & 66 & 59,45 & 11 & 9,90 & 2 & 1,80 & 32 & 28,85 \\
\hline CONTRASTA & 25 & 40,32 & 14 & 22,58 & 0 & 0 & 23 & 37,09 \\
\hline CORRES & 116 & 51,78 & 58 & 25,89 & 37 & 16,51 & 13 & 5,80 \\
\hline LAGRÁN & 72 & 47,05 & 26 & 16,99 & 5 & 3,26 & 50 & 32,6 \\
\hline LAMINORIA & 6 & 5,04 & 12 & 10,08 & 14 & 11,76 & 87 & 73,10 \\
\hline MARQUINEZ & 50 & 30,86 & 61 & 37,65 & 3 & 1,85 & 48 & 29,62 \\
\hline ORBISO & 6 & 10,90 & 8 & 14,54 & 1 & 1,81 & 40 & 72,72 \\
\hline OTEO & 37 & 10,05 & 306 & 83,15 & 18 & 4,89 & 7 & 1,90 \\
\hline PENACERRADA & 57 & 59,37 & 6 & 6,25 & 8 & 8,33 & 26 & 27,08 \\
\hline PIPAON & 36 & 35,64 & 23 & 22,77 & 33 & 32,67 & 9 & 8,91 \\
\hline QUINTANA & 31 & 47,69 & 28 & 43,07 & 0 & 0 & 6 & 9,23 \\
\hline SAN ROMÁN DE CAMPEZO & 18 & 16,82 & 42 & 39,25 & 1 & 0,93 & 46 & 42,99 \\
\hline SAN VICENTE DE ARANA & 142 & 28,6 & 52 & 10,48 & 91 & 18,34 & 209 & 42,13 \\
\hline SANTA CRUZ DE CAMPEZO & & & & & &
\end{tabular}

\section{RIOJA ALAVESA}

\begin{tabular}{|c|c|c|c|c|c|c|c|c|}
\hline & $\mathrm{HA}$ & $\%$ & $\mathrm{CEDA}$ & $\%$ & $\mathrm{FP}$ & $\%$ & PNV & $\%$ \\
\hline BANOS DE EBRO & 108 & 63,90 & 27 & 15,97 & 34 & 20,11 & 0 & 0 \\
\hline BARRIOBUSTO & 105 & 66,45 & 47 & 29,74 & 6 & 3,79 & 0 & 0 \\
\hline CRIPÁN & 43 & 35,53 & 0 & 0 & 2 & 1,65 & 76 & 62,80 \\
\hline ELCIEGO & 234 & 38,55 & 92 & 15,15 & 215 & 35,42 & 66 & 10,87 \\
\hline ELVILLAR & 135 & 49,81 & 30 & 11,07 & 70 & 25,83 & 31 & 11,43 \\
\hline LABASTIDA & 217 & 44,19 & 65 & 13,23 & 198 & 40,32 & 9 & 1,83 \\
\hline LABRAZA & 47 & 50,53 & 38 & 40,86 & 6 & 6,45 & 0 & 0 \\
\hline LAGUARDIA & 589 & 57,91 & 85 & 8,35 & 291 & 28,61 & 48 & 4,71 \\
\hline LANCIEGO & 197 & 55,96 & 5 & 1,42 & 99 & 28,12 & 51 & 14,48 \\
\hline LAPUEBLA DE LABARCA & 77 & 24,21 & 74 & 23,27 & 159 & 50 & 6 & 1,88 \\
\hline LEZA & 27 & 17,53 & 2 & 1,29 & 95 & 61,68 & 30 & 19,48 \\
\hline MOREDA & 137 & 53,72 & 65 & 25,49 & 45 & 17,64 & 8 & 3,13 \\
\hline NAVARIDAS & 50 & 38,75 & 36 & 27,90 & 41 & 31,78 & 2 & 1,55 \\
\hline OYÓN & 165 & 35,79 & 193 & 41,86 & 74 & 16,05 & 28 & 6,07 \\
\hline SALINILLAS DE BURADÓN & 106 & 56,38 & 0 & 0 & 81 & 43,08 & 0 & 0 \\
\hline SAMANIEGO & 49 & 36,02 & 4 & 2,94 & 80 & 58,82 & 3 & 2,20 \\
\hline VILLABUENA & 83 & 50,92 & 13 & 7,97 & 44 & 26,99 & 21 & 12,88 \\
\hline YÉCORA & 150 & 65,78 & 52 & 22,80 & 24 & 10,52 & 0 & 0 \\
\hline
\end{tabular}

VALLES ALAVESES

\begin{tabular}{|c|c|c|c|c|c|c|c|c|}
\hline & HA & $\%$ & CEDA & $\%$ & FP & $\%$ & PNV & $\%$ \\
\hline ARMINON & 91 & 56,52 & 60 & 37,26 & 6 & 3,72 & 2 & 1,24 \\
\hline BERANTEVILLA & 257 & 71,38 & 11 & 3,05 & 79 & 21,94 & 10 & 2,77 \\
\hline BERGUENDA & 195 & 55,24 & 18 & 5,09 & 56 & 15,86 & 84 & 23,79 \\
\hline CUARTANGO & 190 & 59,19 & 33 & 10,28 & 86 & 26,79 & 10 & 3,11 \\
\hline RIBERA ALTA & 342 & 53,85 & 197 & 31,02 & 49 & 7,71 & 46 & 7,24 \\
\hline RIBERA BAJA & 168 & 54,36 & 13 & 4,20 & 98 & 31,71 & 30 & 9,70 \\
\hline SALCEDO & 140 & 46,66 & 107 & 35,66 & 3 & 1 & 49 & 16,33 \\
\hline SALINAS DE AÑANA & 168 & 58,13 & 22 & 7,61 & 12 & 4,15 & 87 & 30,10 \\
\hline VALDEGOVIA & 805 & 57,41 & 108 & 7,70 & 77 & 5,49 & 408 & 29,10 \\
\hline VALDEREJO & 43 & 39,09 & 46 & 41,81 & 0 & 0 & 20 & 18,18 \\
\hline ZAMBRANA & 277 & 76,94 & 33 & 9,16 & 43 & 11,94 & 6 & 1,66 \\
\hline
\end{tabular}

VITORIA

\begin{tabular}{|c|c|c|c|c|c|c|c|c|}
\hline & HA & $\%$ & CEDA & $\%$ & FP & $\%$ & PNV & $\%$ \\
\hline CASCO URBANO & 3.550 & 24,06 & 3.882 & 26,31 & 5078 & 34,42 & 2.108 & 15,21 \\
\hline NUCLEOS RURALES & 858 & 41,5 & 508 & 24,6 & 307 & 14,08 & 394 & 19 \\
\hline
\end{tabular}

